\title{
Otoacoustic emissions and contralateral suppression in tinnitus sufferers with normal hearing
}

\author{
Doaa Elmoazen ${ }^{*}$, Hesham Kozou and Basma Elabassiery
}

\begin{abstract}
Background: The general consensus on the role of hearing loss in generating tinnitus is not relevant in tinnitus patients with normal hearing thresholds. One source of tinnitus may be related to damage to outer hair cells $(\mathrm{OHC})$ of the cochlea. If the $\mathrm{OHC}$ of the human cochlea are to be involved in the generation of tinnitus, testing of Otoacoustic emissions (OAE) could provide a reliable means of recording $\mathrm{OHC}$ dysfunction. We investigated the role of $\mathrm{OHC}$ and cochlear efferent system in tinnitus development in normal hearing ears through studying of Distortion Product Otoacoustic Emissions (DPOAE) and Transient Evoked Otoacoustic Emissions (TEOAE) amplitudes, contralateral suppression amplitudes and suppression value in 15 normal hearing tinnitus patients and 15 control subjects.

Results: Mean f2 DPOAE amplitudes and contralateral suppression were significantly lower in tinnitus group compared to controls for all frequencies from 1001 to $6348 \mathrm{~Hz}$. Suppression values of DPOAEs revealed lower but not significant difference between tinnitus and control groups for all frequencies except 1587 and $6348 \mathrm{~Hz}$. TEOAE amplitudes and contralateral suppression were significantly lower in tinnitus groups for all frequencies from 1000 to $4000 \mathrm{~Hz}$ compared to the control group. Suppression value of TEOAEs revealed no significant difference between the two groups for all frequencies except 3000 and $4000 \mathrm{~Hz}$ were significantly lower in the tinnitus group compared to the control group.
\end{abstract}

Conclusions: Normal hearing manifested by pure tone audiometry in non-vascular tinnitus sufferers does not exclude $\mathrm{OHC}$ and/or cochlear efferent pathology.

Keywords: Tinnitus, Normal hearing, Transient otoacoustic emission, Distortion product otoacoustic emission, Contralateral suppression

\section{Background}

Tinnitus is characterized by the perception of sound in the absence of an external stimulus [1]. Tinnitus may be buzzing, hissing or ringing in the ears, but it can also be intermittent or pulsatile $[2,3]$.

Tinnitus might be associated with abnormalities at any level of the auditory pathway; however, it commonly starts in the cochlea [3]. Jastreboff considers that tinnitus usually starts in the cochlea and then generates abnormal activity

* Correspondence: doaa.elmoazen@alexmed.edu.eg

Audiology Unit, Department of Otorhinolaryngology, Faculty of Medicine, Alexandria University, Alexandria, Egypt

(c) The Author(s). 2020 Open Access This article is licensed under a Creative Commons Attribution 4.0 International License, which permits use, sharing, adaptation, distribution and reproduction in any medium or format, as long as you give appropriate credit to the original author(s) and the source, provide a link to the Creative Commons licence, and indicate if changes were made. The images or other third party material in this article are included in the article's Creative Commons licence, unless indicated otherwise in a credit line to the material. If material is not included in the article's Creative Commons licence and your intended use is not permitted by statutory regulation or exceeds the permitted use, you will need to obtain permission directly from the copyright holder. To view a copy of this licence, visit http://creativecommons.org/licenses/by/4.0/.

in the central pathway, which lead to propagation of the symptom [4].

Nonetheless, the absence of audiometric hearing loss challenges the cochlear theories of tinnitus generation in normal hearing tinnitus patients [2]. Evidence indicates that changes in the cochlea can be detected by otoacoustic emissions (OAEs), contralateral suppression, and suppression value testing even before the occurrence of considerable changes in the patient's audiogram [5].

The OAEs are produced by the outer hair cells (OHCs) of the cochlea as a result of nonlinear active
Springer Open 
mechanical feedback processes, which can be either spontaneous or evoked by sounds [6].

\section{Transient evoked otoacoustic emissions (TEOAEs)}

They are low intensity responses produced by the cochlea emitted after a short acoustic stimulus (clicks or tone bursts). They occur over a wide range of frequencies, thus permitting broad stimulation of the cochlea $[7,8]$. TEOAEs are identified in individuals with normal $\mathrm{OHC}$ function at the frequency analyzed, or in individuals with auditory thresholds below $30 \mathrm{dBHL}$. TEOAE is able to detect impaired hearing but not the type and degree of impairment $[9,10]$.

For measuring TEOAE, in contrast to the recording techniques utilized for spontaneous otoacoustic emissions (SOAEs), the acoustic probe must incorporate a means for presenting stimuli $[11,12]$. To detect TEOAE, signal of the microphone is averaged by time locking it to the transient stimulus. The average waveform is then analyzed to obtain a frequency spectrum of the emissions and validate the response $[13,14]$. Dominant TEOAE frequencies are most often measured within the frequency range extending from 0.5 to $4 \mathrm{kHz}$ and in general have the greatest amplitude between 1 and $1.5 \mathrm{kHz}$, which reflects the middle ear function as suggested by Kemp [15].

\section{Distortion product otoacoustic emissions (DPOAEs)}

Like TEOAE, DPOAEs are sounds generated by OHCs in response to simultaneous stimulation with two pure tones ( $\mathrm{f} 1$ and $\mathrm{f} 2$ ) with closely related frequencies ( $\mathrm{f} 2 / \mathrm{f} 1=$ 1.22). The lower-frequency pure tone is referred to as primary f1, and its intensity level is L1. The higherfrequency tone is $\mathrm{f} 2$, and its intensity level is L2. The parameters analyzed in DPOAE testing are amplitude of the signal and signal to noise ratio (SNR) [16].

Acoustic distortion products represent evoked nonlinear responses because they consist of new frequencies that are not present in the eliciting stimuli. A bi-tonal stimulus with certain properties can elicit many different distortion products (DP) called "intermodulation products." It is the non-linear properties of the cochlea that are responsible for generating such distortion that are detected in the ear canal. In human ears, the largest DPOAE is at the frequency described by the expression 2fl-f2 [16].

\section{Contralateral otoacoustic emission suppression}

The OAE suppression test assesses the efferent auditory system by measuring amplitude suppression or changes in the latency and phase of evoked OAEs when an acoustic stimulus is introduced simultaneously to the contralateral ear [17].
Analysis of the suppression effect permits evaluation of the cochlear status and the central auditory mechanisms, specifically, the efferent medial olivocochlear system [18].

The suppression value is calculated as the difference between the values obtained in the presence and absence of the stimulus. A suppression effect is considered present when there is a reduction of at least $0.5 \mathrm{~dB}$ sound pressure level (SPL) in OAE amplitudes in the presence of a contralateral noise. A suppression effect of 0.5 to $1 \mathrm{~dB}$ SPL indicates integrity of the medial olivocochlear system $[19,20]$.

Several studies have attempted to reveal the relation between tinnitus and OAE amplitudes [21-23] or OAE contralateral suppression amplitudes [24, 25]. Evidence indicates that subtle changes in cochlear function can be detected by OAE testing even before the occurrence of significant changes in the patient's audiogram.

If the $\mathrm{OHCs}$ are to be involved in the generation of tinnitus, testing of OAEs could provide a reliable means of recording $\mathrm{OHC}$ dysfunction. We investigated $\mathrm{OAE}$ as an objective, non-invasive clinical test for the exploration of $\mathrm{OHC}$ integrity and the neurologic evaluation of the descending efferent auditory system in normal hearing tinnitus patients for a better understanding of the function of the auditory pathway.

\section{Aim of the work}

- Investigate the role of outer hair cells and cochlear efferent system in tinnitus development in normal hearing ears through studying of DPOAE and TEOAE amplitudes, contralateral suppression amplitudes, and suppression value.

\section{Methods}

This prospective research was done on 15 normal hearing tinnitus patients (30 ears) and 15 sex- and agematched control subjects (30 ears).

Full history taking, otoscopy examination, tympanometry, acoustic reflex, and pure tone audiometry (air conduction, $250-8000 \mathrm{~Hz}$; bone conduction, $250-4000$ $\mathrm{Hz}$ ) were conducted. Otoacoustic emission test was done using the ILO-96 DP Otodynamic analyzer-version 5.

\section{DPOAE measurement}

Two pure-tone signals, $\mathrm{f} 1$ and $\mathrm{f} 2$ ( $\mathrm{f} 1<\mathrm{f} 2$; f2/f1 $=1.22$ ), were presented simultaneously as primary tone frequencies that generate 2f1-f2 distortion product. Otoacoustic distortion product "audiogram" (DP-Gram) was collected at 3 points/octave steps at a stimulus level of 65 $\mathrm{dB}$ SPL for L1 and $55 \mathrm{~dB}$ SPL for L2. The emitted distortion product at $2 \mathrm{f} 1-\mathrm{f} 2$ was generated at a cochlear site near f2, and therefore, the DP absloute 
amplitude findings in $\mathrm{dB}$ SPL were displayed with respect to frequencies of $\mathrm{f} 2$ that ranged from 1 to $6 \mathrm{kHz}$.

\section{TEOAE measurement}

TEOAEs SNR measurements were recorded according to the non-linear protocol, using acoustical bandwidth $(1000-4000 \mathrm{~Hz})$ at $88 \mathrm{~dB} \mathrm{SPL}$, whose responses were stored and averaged in two 20-ms buffers. Each measurement run was stopped after averaging 260 sweeps.

\section{Measurement in the presence of contralateral suppression (CS)}

DPOAEs and TEOAEs were performed with contralateral white noise of $50 \mathrm{~dB}$ sensation level (SL).

\section{The suppression value}

Suppression value is the difference between the values obtained in the presence and absence of a contralateral stimulus. A suppression effect $\geq 1 \mathrm{~dB}$ SPL indicates integrity of the medial olivo-cochlear system. In this respect, absence of suppression was considered when there is no reduction of at least $1 \mathrm{~dB}$ SPL in OAE amplitudes in the presence of a contralateral noise.

\section{Statistical analysis of the data}

Data were fed to the computer and analyzed using IBM SPSS software package version 20.0. Significance of the obtained results was judged at the $5 \%$ level. $P$ values $\leq$ 0.05 were considered statistically significant

For demographic data: The chi-square test was used for categorical variables, Fisher's exact or Monte Carlo correction was used as a correction for chi-square when more than $20 \%$ of the cells have expected count less than 5, and Student's $t$ test was used to compare normally distributed quantitative variables. For comparing DPOAE, contralateral suppression DPOAE, TEOAE, and contralateral suppression TEOAE amplitudes between the study and control groups, Mann-Whitney test was used. The Spearman coefficient was used to study the correlation between TEOAEs and DPOAE amplitudes and between TEOAE and DPOAE CS.

\section{Results}

\section{Demographic data}

Patients were selected between 20 and 49 years because in this age group the OAEs are fairly stable [26]. The two study groups were homogeneous with respect to age and gender. A comparable number of right and left ears were present in both groups. All subjects had normal auditory thresholds $(25 \mathrm{~dB})$ in the frequencies from 250 to $8000 \mathrm{~Hz}$; normal otoscopy, normal tympanometry results, and stapedial reflexes were present. In our research, there was no statistically significant difference between sex and age of tinnitus subjects and controls.
Table 1 DPOAE amplitudes in dB SPL according to 2f1-f2 in tinnitus patients and control groups

\begin{tabular}{|c|c|c|c|c|}
\hline $2 f 1-f 2$ & $\begin{array}{l}\text { Cases }(n=15) \\
\text { Ears }=30\end{array}$ & $\begin{array}{l}\text { Control }(n=15) \\
\text { Ears }=30\end{array}$ & $U$ & $p$ \\
\hline \multicolumn{5}{|l|}{$818(f 1) 1001(f 2)$} \\
\hline Min.-max. & - 8.80 to 12.50 & 3.90 to 16.30 & $198.50^{*}$ & $<0.001^{*}$ \\
\hline Mean \pm SD. & $7.42 \pm 4.87$ & $11.04 \pm 2.58$ & & \\
\hline Median & 8.40 & 11.60 & & \\
\hline \multicolumn{5}{|l|}{ 1038(f1) $1257(f 2)$} \\
\hline Min.-max. & - 12.80 to 14.90 & 3.20 to 14.0 & $223.50^{*}$ & $0.001^{*}$ \\
\hline Mean \pm SD & $6.77 \pm 5.83$ & $10.95 \pm 2.95$ & & \\
\hline Median & 8.25 & 12.05 & & \\
\hline \multicolumn{5}{|l|}{$1306(f 1) 1587(f 2)$} \\
\hline Min.-max. & $-9.30-15.80$ & 5.90 to 16.50 & $122.50^{*}$ & $<0.001^{*}$ \\
\hline Mean \pm SD. & $5.49 \pm 6.18$ & $12.23 \pm 2.60$ & & \\
\hline Median & 6.50 & 12.20 & & \\
\hline \multicolumn{5}{|l|}{ 1636(f1) 2002(f2) } \\
\hline Min.-max. & - 16.10 to 15.0 & 6.20 to 21.0 & $189.00^{*}$ & $<0.001^{*}$ \\
\hline Mean \pm SD & $5.56 \pm 8.26$ & $12.49 \pm 3.50$ & & \\
\hline Median & 8.20 & 12.10 & & \\
\hline \multicolumn{5}{|l|}{ 2063(f1) 2515(f2) } \\
\hline Min.-max. & - 9.30 to 15.60 & 8.20 to 19.60 & $176.50^{*}$ & $<0.001^{*}$ \\
\hline Mean \pm SD & $7.18 \pm 6.95$ & $13.77 \pm 3.31$ & & \\
\hline Median & 8.95 & 13.55 & & \\
\hline \multicolumn{5}{|l|}{ 2600(f1) 3174(f2) } \\
\hline Min.-max. & -7.30 to 16.10 & -5.30 to 17.30 & $200.50^{*}$ & $<0.001^{*}$ \\
\hline Mean $\pm S D$ & $5.73 \pm 6.77$ & $12.14 \pm 5.20$ & & \\
\hline Median & 6.20 & 12.85 & & \\
\hline \multicolumn{5}{|c|}{ 3284(f1) 4004(f2) } \\
\hline Min.-max. & - 9.90 to 15.20 & 1.0 to 17.10 & $98.50^{*}$ & $<0.001^{*}$ \\
\hline Mean \pm SD & $5.37 \pm 5.57$ & $12.49 \pm 3.20$ & & \\
\hline Median & 5.75 & 12.55 & & \\
\hline \multicolumn{5}{|l|}{$4126(f 1) 5042(f 2)$} \\
\hline Min.-max. & - 13.0 to 19.40 & 4.40 to 21.40 & $271.00^{*}$ & $0.008^{*}$ \\
\hline Mean \pm SD & $8.26 \pm 7.44$ & $13.15 \pm 4.23$ & & \\
\hline Median & 8.35 & 12.75 & & \\
\hline \multicolumn{5}{|l|}{$5200(f 1) 6348(f 2)$} \\
\hline Min.-max. & - 18.60 to 11.0 & -21.20 to 12.20 & $127.50^{*}$ & $<0.001^{*}$ \\
\hline Mean \pm SD & $-7.92 \pm 8.43$ & $4.47 \pm 8.24$ & & \\
\hline Median & -11.85 & 7.60 & & \\
\hline
\end{tabular}

$U, p, U$ and $p$ values for Mann-Whitney test for comparing between the two groups

*Statistically significant at $p \leq 0.05$

\section{Analytic data} DPOAE amplitudes

Table 1 shows significantly lower DPOAE amplitudes in tinnitus patients at all frequencies. 
Table 2 Contralateral suppression (CS) of DPOAE amplitudes in dB SPL according to 2f1-f2 in tinnitus patients and control group

\begin{tabular}{|c|c|c|c|c|}
\hline CS DPOAE (2f1-f2) & $\begin{array}{l}\text { Cases }(n=15) \\
\text { Ears }=30\end{array}$ & $\begin{array}{l}\text { Control }(n=15) \\
\text { Ears }=30\end{array}$ & U & $p$ \\
\hline \multicolumn{5}{|l|}{$818(f 1) 1001(f 2)$} \\
\hline Min.-max. & -15.80 to 10.80 & -3.40 to 11.50 & $297.00^{*}$ & $0.024^{*}$ \\
\hline Mean \pm SD. & $1.58 \pm 6.82$ & $5.08 \pm 4.18$ & & \\
\hline Median & 3.90 & 6.15 & & \\
\hline \multicolumn{5}{|l|}{$1038(f 1) 1257(f 2)$} \\
\hline Min.-max. & -15.90 to 12.70 & -6.10 to 10.90 & $305.00^{*}$ & $0.032^{*}$ \\
\hline Mean $\pm S D$ & $1.06 \pm 7.21$ & $4.86 \pm 4.77$ & & \\
\hline Median & 1.80 & 6.20 & & \\
\hline \multicolumn{5}{|l|}{$1306(f 1)$ 1587(f2) } \\
\hline Min.-max. & -13.40 to 14.20 & -10.20 to 14.50 & $264.00^{*}$ & $0.006^{*}$ \\
\hline Mean \pm SD & $0.78 \pm 6.62$ & $5.55 \pm 5.92$ & & \\
\hline Median & 1.65 & 7.60 & & \\
\hline \multicolumn{5}{|l|}{$1636(f 1) 2002(f 2)$} \\
\hline Min.-max. & -28.90 to 11.40 & -8.70 to 15.60 & $240.50^{*}$ & $0.002^{*}$ \\
\hline Mean \pm SD. & $-1.03 \pm 8.74$ & $5.47 \pm 6.09$ & & \\
\hline Median & 0.55 & 6.55 & & \\
\hline \multicolumn{5}{|l|}{$2063(f 1) 2515(f 2)$} \\
\hline Min.-max. & - 20.0 to 10.20 & - 9.90 to 15.20 & $241.00^{*}$ & $0.002^{*}$ \\
\hline Mean \pm SD & $-1.42 \pm 7.37$ & $4.86 \pm 6.34$ & & \\
\hline Median & 0.10 & 5.20 & & \\
\hline \multicolumn{5}{|l|}{$2600(f 1) 3174(f 2)$} \\
\hline Min.-max. & -13.40 to 10.10 & -13.40 to 12.70 & $241.00^{*}$ & $0.002^{*}$ \\
\hline Mean $\pm S D$ & $-1.44 \pm 5.75$ & $3.51 \pm 6.74$ & & \\
\hline Median & -2.85 & 5.25 & & \\
\hline \multicolumn{5}{|l|}{ 3284(f1) 4004(f2) } \\
\hline Min.-max. & -14.20 to 11.80 & - 19.0 to 11.20 & $183.00^{*}$ & $<0.001^{*}$ \\
\hline Mean \pm SD & $-0.86 \pm 6.42$ & $4.72 \pm 6.61$ & & \\
\hline Median & 0.90 & 5.95 & & \\
\hline \multicolumn{5}{|l|}{$4126(f 1) 5042(f 2)$} \\
\hline Min.-max. & - 16.50 to 19.10 & -2.0 to 16.90 & $305.5^{*}$ & $0.033^{*}$ \\
\hline Mean $\pm S D$ & $5.67 \pm 8.55$ & $10.08 \pm 3.88$ & & \\
\hline Median & 4.20 & 10.15 & & \\
\hline \multicolumn{5}{|l|}{$5200(f 1) 6348(f 2)$} \\
\hline Min.-max. & -20.90 to 10.10 & -33.50 to 8.60 & $213.00^{*}$ & $<0.001^{*}$ \\
\hline Mean $\pm S D$ & $-11.03 \pm 9.32$ & $-1.59 \pm 10.0$ & & \\
\hline Median & -15.70 & 1.65 & & \\
\hline
\end{tabular}

$U, p U$ and $p$ values for Mann-Whitney test for comparing between the two groups

*Statistically significant at $p \leq 0.05$

\section{DPOAE amplitudes with contralateral suppression}

Table 2 shows significantly lower contralateral suppression of DPOAE amplitudes in tinnitus patients at all frequencies.

\section{Suppression value of DPOAE amplitudes}

Table 3 shows significant reduction of DPOAE suppression value in tinnitus patients in 1587 and $6348 \mathrm{~Hz}\left(\mathrm{f}_{2}\right.$ frequencies) compared to the control group. 
Table 3 Comparison between the two studied groups according to suppression value in DPOAE amplitudes (dB SPL)

\begin{tabular}{|c|c|c|c|c|}
\hline Suppression value & $\begin{array}{l}\text { Cases }(n=15) \\
\text { Ears }=30\end{array}$ & $\begin{array}{l}\text { Control }(n=15) \\
\text { Ears }=30\end{array}$ & $U$ & $p$ \\
\hline \multicolumn{5}{|l|}{$818(f 1) 1001(f 2)$} \\
\hline Min.-max. & 0.10 to 14.70 & 2.0 to 12.0 & 424.50 & 0.706 \\
\hline Mean \pm SD. & $5.84 \pm 4.39$ & $5.96 \pm 2.68$ & & \\
\hline Median & 6.10 & 5.10 & & \\
\hline \multicolumn{5}{|l|}{$1038(f 1) 1257(f 2)$} \\
\hline Min.-max. & 0.10 to 21.50 & 1.40 to 13.0 & 375.50 & 0.271 \\
\hline Mean \pm SD. & $5.70 \pm 5.17$ & $6.10 \pm 3.59$ & & \\
\hline Median & 4.05 & 4.90 & & \\
\hline \multicolumn{5}{|l|}{ 1306(f1) 1587(f2) } \\
\hline Min.-max. & 0.50 to 16.20 & 1.80 to 19.10 & $297.00^{*}$ & $0.024^{*}$ \\
\hline Mean \pm SD. & $4.71 \pm 3.69$ & $6.68 \pm 4.05$ & & \\
\hline Median & 3.35 & 6.0 & & \\
\hline \multicolumn{5}{|l|}{$1636(f 1) 2002(f 2)$} \\
\hline Min.-max. & 0.0 to 20.40 & 1.60 to 16.80 & 404.00 & 0.496 \\
\hline Mean \pm SD. & $6.60 \pm 5.17$ & $7.02 \pm 4.18$ & & \\
\hline Median & 6.80 & 5.70 & & \\
\hline \multicolumn{5}{|l|}{ 2063(f1) 2515(f2) } \\
\hline Min.-max. & 0.20 to 21.60 & 1.20 to 19.60 & 429.50 & 0.762 \\
\hline Mean \pm SD. & $8.60 \pm 5.56$ & $9.11 \pm 5.46$ & & \\
\hline Median & 8.05 & 9.05 & & \\
\hline \multicolumn{5}{|l|}{$2600(f 1) 3174(f 2)$} \\
\hline Min.-max. & 0.20 to 17.60 & 1.90 to 18.0 & 353.50 & 0.154 \\
\hline Mean $\pm S D$ & $7.13 \pm 5.03$ & $8.62 \pm 4.31$ & & \\
\hline Median & 6.90 & 8.05 & & \\
\hline \multicolumn{5}{|l|}{ 3284(f1) 4004(f2) } \\
\hline Min.-max. & 0.30 to 23.20 & 1.20 to 20.0 & 337.50 & 0.096 \\
\hline Mean \pm SD. & $6.22 \pm 5.72$ & $7.77 \pm 4.71$ & & \\
\hline Median & 5.35 & 7.35 & & \\
\hline \multicolumn{5}{|l|}{$4126(f 1) 5042(f 2)$} \\
\hline Min.-max. & 0.0 to 10.60 & -8.1 to 17.90 & 342.0 & 0.110 \\
\hline Mean \pm SD & $2.60 \pm 2.95$ & $3.07 \pm 4.68$ & & \\
\hline Median & 1.50 & 3.30 & & \\
\hline \multicolumn{5}{|l|}{$5200(f 1) 6348(f 2)$} \\
\hline Min.-max. & 0.10 to 7.60 & 1.0 to 20.80 & $260.50^{*}$ & $0.005^{*}$ \\
\hline Mean \pm SD. & $3.08 \pm 2.07$ & $6.06 \pm 4.38$ & & \\
\hline Median & 2.95 & 4.60 & & \\
\hline
\end{tabular}

$U, p U$ and $p$ values for Mann-Whitney test for comparing between the two groups

*Statistically significant at $p \leq 0.05$

\section{TEOAE amplitudes}

Table 4 shows significant decrease of TEOAE amplitudes in tinnitus patients in all five frequencies (1000$4000 \mathrm{~Hz}$ ) compared to the control group.
Table 4 TEOAE amplitudes (SNR) in dB SPL in tinnitus patients and control group

\begin{tabular}{|c|c|c|c|c|}
\hline TEOAES & $\begin{array}{l}\text { Cases }(n=15) \\
\text { Ears }=30\end{array}$ & $\begin{array}{l}\text { Control }(n=15) \\
\text { Ears }=30\end{array}$ & $U$ & $P$ \\
\hline \multicolumn{5}{|l|}{1000} \\
\hline Min.-max. & 1.0 to 17.0 & 7.0 to 20.0 & $241.50^{*}$ & $0.002^{*}$ \\
\hline Mean \pm SD & $8.17 \pm 4.36$ & $12.0 \pm 4.11$ & & \\
\hline Median & 8.0 & 11.0 & & \\
\hline \multicolumn{5}{|l|}{1500} \\
\hline Min.-max. & 4.0 to 27.0 & 9.0 to 25.0 & $296.00^{*}$ & $0.022^{*}$ \\
\hline Mean \pm SD & $13.87 \pm 6.32$ & $17.60 \pm 4.45$ & & \\
\hline Median & 14.50 & 17.0 & & \\
\hline \multicolumn{5}{|l|}{2000} \\
\hline Min.-max. & 7.0 to 26.0 & 6.0 to 28.0 & $291.50^{*}$ & $0.019 *$ \\
\hline Mean \pm SD & $15.27 \pm 5.10$ & $18.30 \pm 5.43$ & & \\
\hline Median & 14.0 & 19.0 & & \\
\hline \multicolumn{5}{|l|}{3000} \\
\hline Min.-max. & 1.0 to 19.0 & 14.0 to 24.0 & $24.00^{*}$ & $<0.001^{*}$ \\
\hline Mean \pm SD. & $10.23 \pm 4.49$ & $20.40 \pm 2.59$ & & \\
\hline Median & 9.0 & 20.50 & & \\
\hline \multicolumn{5}{|l|}{4000} \\
\hline Min.-max. & 2.0 to 20.0 & 11.0 to 26.0 & $200.50^{*}$ & $<0.001^{*}$ \\
\hline Mean \pm SD. & $10.43 \pm 5.10$ & $15.87 \pm 3.06$ & & \\
\hline Median & 9.0 & 15.0 & & \\
\hline
\end{tabular}

$U, p U$ and $p$ values for Mann-Whitney test for comparing between the two groups

*Statistically significant at $p \leq 0.05$

TEOAE amplitudes with contralateral suppression

Table 5 shows significant reduction of TEOAE amplitudes in tinnitus patients in all five frequencies (1000$4000 \mathrm{~Hz}$ ) compared to the control group.

\section{Suppression value of TEOAE amplitudes}

Table 6 shows significant reduction of TEOAE amplitudes in tinnitus patients in high frequencies (3000 and $4000 \mathrm{~Hz}$ ) compared to the control group.

\section{Suppression value in tinnitus patients}

The percentage of tinnitus ears with DPOAE suppression $\geq 1 \mathrm{~dB}$ SPL was $40 \%$ (Fig. 1) while the percentage of tinnitus ears with TEOAE suppression was $60 \%$ (Fig. 2).

\section{Correlation between TEOAE and DPOAE amplitudes}

Table 7 shows the correlation between TEOAE amplitudes and $\mathrm{f} 2$ of DPOAE amplitudes without noise in tinnitus patients (30 ears) in five test frequencies. No correlation was found between the two tests. 
Table 5 Contralateral suppression of TEOAE SNR amplitudes ( $d B$ $S P L)$ in tinnitus patients and control group

\begin{tabular}{|c|c|c|c|c|}
\hline CS TEOAE & $\begin{array}{l}\text { Cases }(n=15) \\
\text { Ears }=30\end{array}$ & $\begin{array}{l}\text { Control }(n=15) \\
\text { Ears }=30\end{array}$ & $U$ & $p$ \\
\hline \multicolumn{5}{|l|}{1000} \\
\hline Min.-max. & - 5.0 to 17.0 & 2.0 to 18.0 & $245.50^{*}$ & $0.002^{*}$ \\
\hline Mean \pm SD & $4.20 \pm 4.44$ & $8.07 \pm 4.45$ & & \\
\hline Median & 4.0 & 7.0 & & \\
\hline \multicolumn{5}{|l|}{1500} \\
\hline Min.-max. & 0.0 to 18.0 & 4.0 to 20.0 & $299.50^{*}$ & $0.026^{*}$ \\
\hline Mean $\pm S D$ & $8.07 \pm 5.52$ & $11.17 \pm 4.51$ & & \\
\hline Median & 7.0 & 10.50 & & \\
\hline \multicolumn{5}{|l|}{2000} \\
\hline Min.-max. & 0.0 to 24.0 & 5.0 to 23.0 & $282.0^{*}$ & $0.013^{*}$ \\
\hline Mean \pm SD & $10.40 \pm 5.37$ & $13.57 \pm 4.59$ & & \\
\hline Median & 9.50 & 14.0 & & \\
\hline \multicolumn{5}{|l|}{3000} \\
\hline Min.-max. & 0.0 to 16.0 & 6.0 to 19.0 & $261.50^{*}$ & $0.005^{*}$ \\
\hline Mean \pm SD & $7.70 \pm 4.57$ & $10.83 \pm 2.72$ & & \\
\hline Median & 6.50 & 11.0 & & \\
\hline \multicolumn{5}{|l|}{4000} \\
\hline Min.-max. & 0.0 to 18.0 & 6.0 to 21.0 & $308.50^{*}$ & $0.036^{*}$ \\
\hline Mean \pm SD. & $7.93 \pm 5.51$ & $10.40 \pm 3.31$ & & \\
\hline Median & 6.0 & 10.0 & & \\
\hline
\end{tabular}

$U, p U$ and $p$ values for Mann-Whitney test for comparing between the two groups

*Statistically significant at $p \leq 0.05$

\section{Correlation between contralateral suppression of TEOAE and DPOAE amplitudes}

Figure 3 shows the correlation between CS TEOAE and CS DPOAE (f2) amplitudes in tinnitus patients (30 ears) in four test frequencies. A positive correlation was found between the two tests in frequencies $(1000,1500,2000$, and $3000 \mathrm{~Hz}$ ), and no correlation was found in $4000 \mathrm{~Hz}$.

\section{Discussion}

\section{Demographic data}

In this research, the tinnitus female patients were $80 \%$ (12 patients) and the tinnitus male patients were 20\% (3 patients) that might be due to the higher incidence of annoyance in females as compared to males.

Davis [27] and Coelho et al. [28] found that female patients gave significantly higher annoyance levels than males. On the other hand, Hiller and Goebel [29] found that males have higher severity of tinnitus.

\section{Analytic data}

Many researchers attempted to reveal an association between tinnitus and OAE amplitudes [21-23] or OAEs contralateral suppression amplitudes [24, 25].
Table 6 Comparison between the two studied groups according to suppression value in TEOAE amplitudes (dB SPL)

Suppression value Cases $(n=15) \quad$ Control $(n=15) \quad U \quad p$ Ears $=30 \quad$ Ears $=30$

1000

Mean \pm SD. $\quad 3.97 \pm 2.81 \quad 3.97 \pm 1.87$

Median $\quad 3.0 \quad 4.0$

1500

$\begin{array}{lllll}\text { Min.-max. } \quad 0.0 \text { to } 17.0 \quad 3.0 \text { to } 15.0 & 366.00 & 0.211\end{array}$

Mean \pm SD. $\quad 5.80 \pm 4.87 \quad 6.20 \pm 3.09$

Median $\quad 4.50 \quad 5.0$

2000

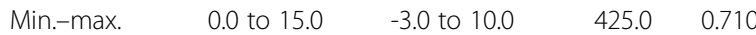

Mean \pm SD. $\quad 4.87 \pm 3.66 \quad 4.73 \pm 3.59$

$\begin{array}{lll}\text { Median } & 4.0 & 5.0\end{array}$

3000

Min.-max. $\quad 0.0$ to $7.0 \quad 3.0$ to $16.0 \quad 17.00^{*}<0.001^{*}$

Mean \pm SD. $\quad 2.53 \pm 1.78 \quad 9.60 \pm 3.11$

Median $\quad 2.50 \quad 9.0$

4000

\begin{tabular}{|c|c|c|}
\hline Min.-max. & 0.0 to 11.0 & 2.0 to 9.0 \\
\hline
\end{tabular}

Mean \pm SD. $\quad 2.50 \pm 2.19 \quad 5.47 \pm 1.93$

$\begin{array}{lll}\text { Median } & 2.0 & 6.0\end{array}$

$U, p U$ and $p$ values for Mann-Whitney test for comparing between the two groups

*Statistically significant at $p \leq 0.05$

Previous studies have demonstrated that OAE can be used to reveal subclinical OHC damage in audiometrically normal ears $[30,31]$.

\section{DPOAE amplitudes}

In the present research, significant reduction of DPOAE amplitude was found in all frequencies in tinnitus

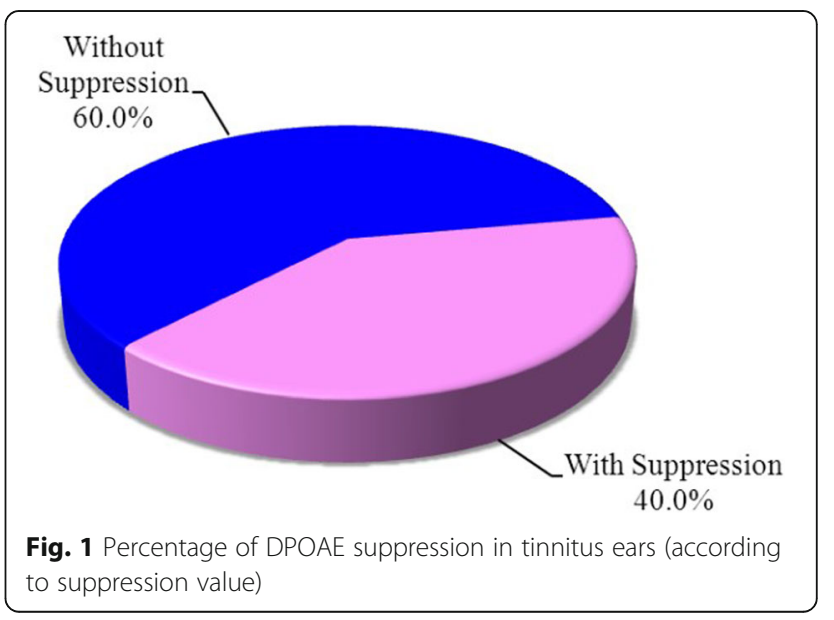




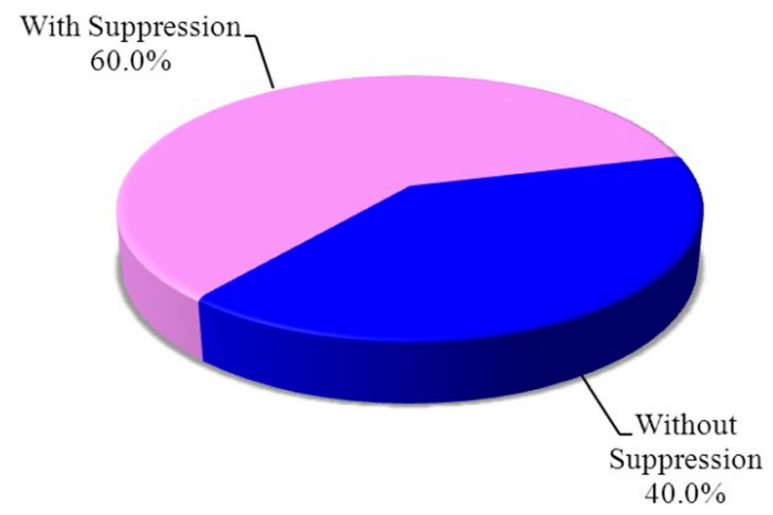

Fig. 2 Percentage of TEOAE suppression in tinnitus ears (according to suppression value)

sufferers. Reduction in DPOAE amplitudes indicates dysfunction of the OHCs. This may be due to the decrease in the $\mathrm{OHC}$ activity which results from the imbalance between the OHCs and IHCs. The OHCs are more liable to damage, and when it occurs, they fail to perform the inhibition over the IHC function. This loss of IHC inhibition results in tinnitus.

Our results are consistent with Shiomi et al. [32], Igna et al. [33], Favero et al. [34], and Liu et al. [35] that there was a significant reduction in DPOAE amplitudes over a wide range of frequencies $(1000-7000 \mathrm{~Hz})$ observed in the normal hearing tinnitus group.

\section{TEOAE amplitudes}

In this research, TEOAE amplitude was significantly reduced in the tinnitus sufferers group in all five frequencies from 1000 to $4000 \mathrm{~Hz}$.

Tinnitus was related to a decrease in TEOAE amplitudes. Fernandes and Santos [25] found a decrease in amplitude in all frequencies in both ears of tinnitus sufferers with normal hearing. Rita and de Azevedo [36] observed a difference in the cases of unilateral tinnitus, with the overall amplitude being lower in the tinnitus ear.

Table 7 Correlation between TEOAE and DPOAE (f2) amplitudes in the patient group $(n=15$, ears $=30)$

\begin{tabular}{lll}
\hline & $\boldsymbol{r}_{\mathbf{s}}$ & $\boldsymbol{p}$ \\
\hline TEOAE 1000 vs. DPOAE $1001(\mathrm{f} 2)$ amplitude & -0.031 & 0.869 \\
TEOAE 1500 vs. DPOAE 1587(f2) amplitude & 0.335 & 0.070 \\
TEOAE 2000 vs. DPOAE 2002(f2) amplitude & 0.267 & 0.154 \\
TEOAE 3000 vs. DPOAE 3174(f2) amplitude & 0.053 & 0.781 \\
TEOAE 4000 vs. DPOAE 4004(f2) amplitude & 0.254 & 0.176 \\
\hline $\boldsymbol{r}_{\text {s }}$ Spearman coefficient & & \\
*Statistically significant at $p \leq 0.05$ & &
\end{tabular}

\section{Contralateral suppression:}

In the current research, suppression was elicited by using contralateral white noise of $50 \mathrm{~dB}$ SL, based on the previous studies on normal hearing subjects without tinnitus [37-39]. So different hearing thresholds differ in the absolute intensity of the suppressor noise.

In this research, the CS DPOAEs were significantly decreased in all nine frequencies in tinnitus sufferers. Also CS TEOAE amplitude was significantly decreased in tinnitus sufferers for all frequencies.

\section{Contralateral suppression DPOAE amplitudes}

Riga et al. [24] investigated CS DPOAEs in 18 tinnitus sufferers with normal hearing using noise of $55 \mathrm{~dB} \mathrm{HL}$. Non-significant lower amplitudes were reported in the tinnitus group compared to controls.

Chéry-Croze et al. [40] evaluated CS DPOAEs using noise of $55 \mathrm{dBSPL}$. They observed that emission suppression was lower in ears with tinnitus.

\section{Contralateral suppression TEOAE amplitudes}

Our results are consistent with the findings of Paglialonga et al. [41] who found lower TEOAE amplitudes and TEOAE suppression in tinnitus groups. This is because of dysfunction of the cochlear active mechanisms implicated in the generation of otoacoustic emissions. Since tinnitus sufferers in this research had normal hearing, poor OAEs indicate subclinical damage to OHCs.

\section{Suppression value}

In the current research, the number of tinnitus subjects without suppression according to the suppression value in DPOAE was $60 \%$ and in TEOAE was $40 \%$. This could be due to the frequency-specific analysis of DPOAE from 1001 to $6348 \mathrm{~Hz}$ which included higher frequencies than TEOAE $(1000$ to $4000 \mathrm{~Hz})$. Additionally, TEOAE stimulates all the cochlear basilar membrane; thus, it gives an overall information of the cochlear hair cell function. Therefore, DPOAE is superior to TEOAE in detecting subtle cochlear anomalies especially at high frequencies.

\section{Correlation between TEOAE and DPOAE amplitudes:}

In this research, no correlation was found between TEOAE and DPOAE amplitudes in tinnitus sufferers in five test frequencies. This could be because of the different protocols used in measurements.

\section{Correlation between CS TEOAE and CS DPOAE amplitudes}

A significant positive correlation was found between CS TEOAE and CS DPOAE amplitudes in tinnitus sufferers in four frequencies $(1000,1500,2000,3000 \mathrm{~Hz})$.

Therefore, contralateral suppression of OAEs is a consistent measurement tool for the determination of 


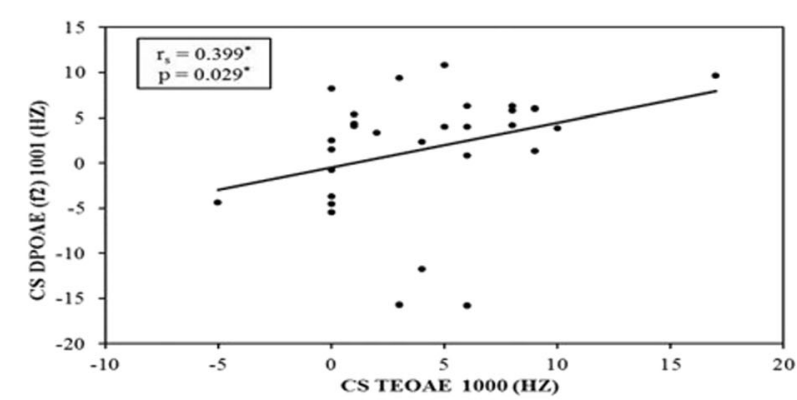

A

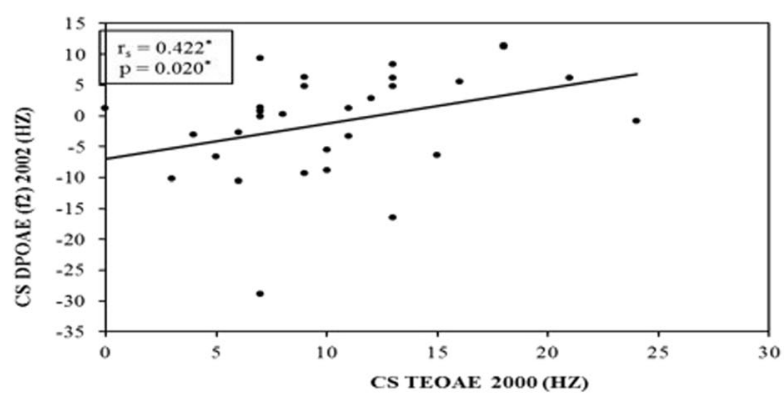

$\mathrm{C}$

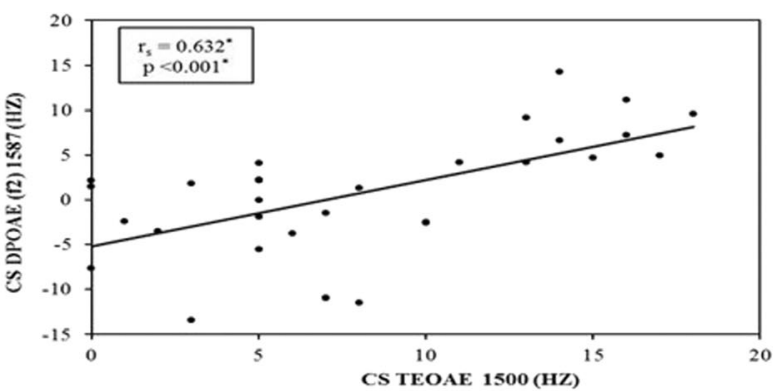

B

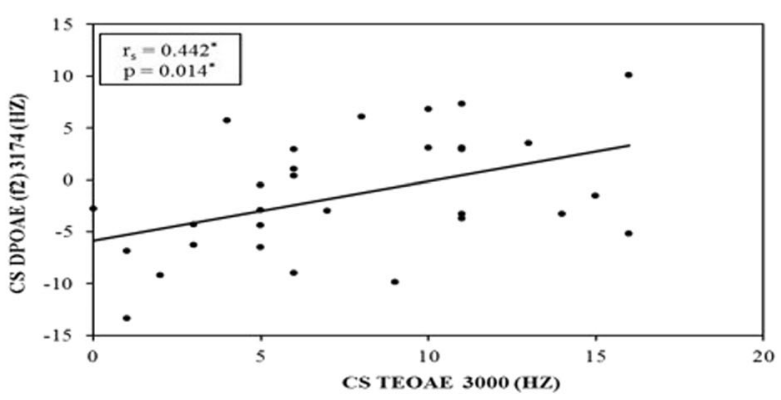

$\mathrm{D}$

Fig. 3 Correlation between CS TEOAE amplitudes and CS DPOAE (f2) amplitudes in cases group ( $n=15$, ears = 30) in 1000, 1500, 2000, and 3000 $\mathrm{Hz}(\mathbf{a}-\mathbf{d})$

abnormal cochlear efferent pathology in tinnitus subjects with normal hearing.

\section{Conclusion}

- Normal hearing manifested by pure tone audiometry in non-vascular tinnitus sufferers does not exclude $\mathrm{OHC}$ and/or cochlear efferent pathology.

- DPOAEs are superior to TEOAEs because they are more frequency specific and so more sensitive in detecting subclinical cochlear dysfunction.

- Contralateral suppression of OAEs can be confidently used in detecting abnormal cochlear efferent pathology in tinnitus sufferers with normal hearing.

\section{Abbreviations}

CS: Contralateral suppression; dB: Decibel; DP: Distortion products; DPGram: Distortion product "audiogram"; DPOAEs: Distortion product otoacoustic emissions; Hz: Hertz; kHz: Kilohertz; OHCs: Outer hair cells; OAEs: Otoacoustic emissions; SL: Sensation level; SNR: Signal to noise ratio; SOAEs: Spontaneous otoacoustic emissions; SPL: Sound pressure level; TEOAEs: Transient evoked otoacoustic emissions

\section{Acknowledgements}

\section{Not applicable}

\section{Authors' contributions}

All authors have read and approved the manuscript. DE, HK and BE done the Statistical analysis. DE and HK done the design, Definition of intellectual content and Manuscript review. DE and BE done the Data analysis and
Clinical studies. DE done the Manuscript editing. HK done the Concepts. BE done the Literature search, Data acquisition and Manuscript preparation.

Funding

None

Availability of data and materials

The datasets used and/or analyzed during the current study are available from the corresponding author on reasonable request.

\section{Ethics approval and consent to participate}

Informed written consent to participate in the study was provided by all participants and approved by Faculty of medicine, Alexandria University Ethics Committee on 24/1/2018 (reference number not available).

\section{Consent for publication}

Not applicable

\section{Competing interests}

The authors declare that they have no competing interests.

Received: 17 April 2020 Accepted: 2 August 2020

Published online: 04 November 2020

\section{References}

1. Langguth B (2011) A review of tinnitus symptoms beyond 'ringing in the ears': a call to action. Curr Med Res Opin 7(8):1635-1643

2. Han BI, Lee HW, Kim TY, Lim JS, Shin KS (2009) Tinnitus: characteristics, causes, mechanisms, and treatments. J Clin Neurol 5(1):11-19

3. Chung JH, Lee SH (2016) The pathophysiologic mechanism of tinnitus. Hanyang Med Rev 36(2):81-85

4. Jastreboff PJ (1990) Phantom auditory perception (tinnitus): mechanisms of generation and perception. Neurosci Res 8(4):221-254

5. Ishak WS, Zhao F, Rajenderkumar D, Arif M (2013) Measurement of subtle auditory deficit in tinnitus patients with normal audiometric thresholds 
using evoked otoacoustic emissions and threshold equalizing noise tests. Int Tinnitus J 18(1):35-44

6. Serra L, Novanta G, Sampaio AL, Augusto Oliveira C, Granjeiro R, Braga SC (2015) The study of otoacoustic emissions and the suppression of otoacoustic emissions in subjects with tinnitus and normal hearing: an insight to tinnitus etiology. Int Arch Otorhinolaryngol 19(2):171-175

7. Durante AS (2011) Otoacoustic emissions. In: Bevilacqua MC, Martinez MAN, Balen SA, Pupo AC, Reis ACMB, Frota S (eds). Audiology Treaty. São Paulo, Brazil: Editora Santos, pp 145-158.

8. Sousa LCA, Piza MRT, Alvarenga KF, Cóser PL (2008) Electrophysiology of hearing and acoustic emissions-principles and clinical applications. In: Souza LCA, Piza MRT, Alvarenga KF, Cóser PL (orgs). São Paulo, Brazil: Editora Tecmedd.

9. Stach A (2000) The audiologist's assessment tools. In: Stach A (ed) Clinical Audiology: An Introduction. Singular Publishing Group, London, UK, pp 292-317

10. Harrison WA, Norton SJ (1999) Characteristics of transient evoked otoacoustic emissions in normal-hearing and hearing-impaired children. Ear Hear 20(1):75-86

11. Zelle D, Dalhoff E, Gummer AW (2017) Comparison of time-domain sourceseparation techniques for short-pulse distortion-product otoacoustic emissions. J Acoust Soc Am 142(6):El544

12. Zelle D, Gummer AW, Dalhoff E (2017) Extraction of distortion-product otoacoustic emission source components and its relevance for objective audiometry. Procedia IUTAM 24:38-47

13. Otometrics GN (2013) AccuScreen OAE \& ABR Screener Test Methods. GN Otometrics A/S, Denmark

14. Mahmood SL (2008) The effect of the menstrual cycle on evoked botoacoustic efferent suppression. University of Maryland, Dissertation

15. Kemp DT (1986) Otoacoustic emissions, travelling waves and cochlear mechanisms. Hear Res 22:95-104

16. Kemp DT (1979) Evidence of mechanical nonlinearity and frequency selective wave amplification in the cochlea. Arch Otorhinolaryngol 224:37-45

17. Kehrle HM, Granjeiro RC, Sampaio AL, Bezerra R, Almeida VF, Oliveira CA (2008) Comparison of auditory brainstem response results in normal-hearing patients with and without tinnitus. Arch Otolaryngol Head Neck Surg 134(6):647-651

18. Leme VN (2009) Otoacoustic emissions: effect of contralateral and bilateral acoustic stimulation on efferent auditory system function. University of São Paulo, Dissertation

19. Collet L, Veuillet E, Bene J, Morgon A (1992) Effects of contralateral white noise on click-evoked emissions in normal and sensorineural ears: towards an exploration of the medial olivocochlear system. Audiology 31(1):1-7

20. Angrisani RMG, Azevedo MF, Pereira LD, Lopes C, Garcia MV (2009) Carriers of vitiligo: study of otoacoustic emissions and suppression effect. Rev Bras Otorrinolaringol 75(1):111-115

21. Granjeiro RC, Kehrle HM, Bezerra RL, Almeida VF, Sampaio AL, Oliveira CA (2008) Transient and distortion product evoked oto-acoustic emissions in normal hearing patients with and without tinnitus. Otolaryngol Head Neck Surg 138(4):502-506

22. Dejonckere PH, Coryn C, Lebacq J (2009) Experience with a medicolegal decision-making system for occupational hearing loss-related tinnitus. Int Tinnitus J 15(2):185-192

23. Modh D, Katarkar A, Alam N, Jain A, Shah P (2014) Relation of distortion product otoacoustic emission and tinnitus in normal hearing patients: a pilot study. Noise Health 16(69):69-72

24. Riga M, Papadas T, Werner JA, Dalchow CV (2007) A clinical study of the efferent auditory system in patients with normal hearing who have acute tinnitus. Otol Neurotol 28(2):185-190

25. Fernandes Lda C, Santos TM (2009) Tinnitus and normal hearing: a study on the transient otoacoustic emissions suppression. Braz J Otorhinolaryngol 75(3):414-419

26. Probst R, Hauser R (1990) Distortion product otoacoustic emissions in normal and hearing-impaired ears. Am J Otolaryngol 11(4):236-243

27. Davis AC (1983) Hearing disorders in the population: first phase findings of the MRC national study of hearing. In: Lutman ME, Haggard MP (eds) Hearing Science and Hearing Disorders. Churchill Livingstone, London, pp 35-60

28. Coelho CCB, Sanchez TG, Bento RF (2004) Characteristics of tinnitus in patients attended at referral service. Arq Int Otorrinolaringol 8(3):284-292
29. Hiller W, Goebel G (2006) Factors influencing tinnitus loudness and annoyance. Arch Otolaryngol Head Neck Surg 132(12):1323-1330

30. Kowalska S, Sulkowski W (2001) Tinnitus in noise-induced hearing impairment. Med Pr 52(5):305-313

31. Attias J, Furst M, Furman V, Reshef I, Horowitz G, Bresloff I (1995) Noiseinduced otoacoustic emission loss with or without hearing loss. Ear Hear 16(6):612-618

32. Shiomi Y, Tsuji J, Naito Y, Fujiki N, Yamamoto N (1997) Characteristics of DPOAE audiogram in tinnitus patients. Hear Res 108:83-88

33. Igna CD, Schmidt LP, Smith M, Facchini L, Kang S (2004) Otoacoustic emission in patients with tinnitus and normal hearing. Otolaryngol Head Neck Surg 131(2):279

34. Favero M, Bento RF, Sanches TG, Nascimento AF (2004) Contra lateral suppression of otoacousti emission in subject with tinnitus. Otolaryngol Head Neck Surg 131(2):260-264

35. Liu B, Liu C, Song BB, Zhao XY (1996) Otoacoustic emissions and tinnitus. Chinese J Otorhinolaryngol 31:231-233

36. Rita M, de Azevedo MF (2005) Otoacoustic emissions and medial olivocochlear system: patients with tinnitus and no hearing loss. Pro Fono 17(3):283-292

37. Veuillet E, Collet L, Duclaux R (1991) Effect of contralateral acoustic stimulation on active cochlear micromechanical properties in human subjects: dependence on stimulus variables. J Neurophysiol 65(3):724-735

38. Hood LJ, Berlin Cl, Hurley A, Cecola RP, Bell B (1996) Contralateral suppression of transient-evoked otoacoustic emissions in humans: intensity effects. Hear Res 101:113-118

39. Velenovsky DS, Glattke TJ (2002) The effect of noise bandwidth on the contralateral suppression of transient evoked otoacoustic emissions. Hear Res 164:39-48

40. Chery-Croze S, Moulin A, Collet L (1993) Effect of contralateral sound stimulation on the distortion product $2 \mathrm{f} 1-\mathrm{f} 2$ in humans: evidence of a frequency specificity. Hear Res 68(1):53-58

41. Paglialonga A, Del Bo L, Ravazzani P, Tognola G (2010) Quantitative analysis of cochlear active mechanisms in tinnitus subjects with normal hearing sensitivity: multiparametric recording of evoked otoacoustic emissions and contralateral suppression. Auris Nasus Larynx 37(3):291-298

\section{Publisher's Note}

Springer Nature remains neutral with regard to jurisdictional claims in published maps and institutional affiliations.

\section{Submit your manuscript to a SpringerOpen ${ }^{\circ}$ journal and benefit from:}

- Convenient online submission

- Rigorous peer review

- Open access: articles freely available online

High visibility within the field

- Retaining the copyright to your article

Submit your next manuscript at $>$ springeropen.com 